\title{
Práticas anticoncorrenciais das gigantes da internet no contexto brasileiro*
}

\author{
Jânia Maria Lopes Saldanha* \\ Guilherme Pittaluga Hoffmeister" \\ Clara Rossatto Bohrz"***
}

Recebido: 18 de novembro de 2017 • Aprovado: 11 de junho de 2018
https://doi.org/10.22395/ojum.v17n34a3

\begin{abstract}
RESUMO
A sociedade em rede potencializa a utilização das tecnologias da informação e comunicação, sobretudo a internet. Grandes empresas que atuam nesse ramo se estabelecem como verdadeiras "gigantes" e determinam novas dinâmicas de poder e desafios a uma regulação democrática da internet. Este trabalho visa mapear algumas práticas anticoncorrenciais das gigantes da internet a partir da análise de algumas decisões do Conselho Administrativo de Defesa Econômica no contexto brasileiro e de outros órgãos responsáveis por coibir práticas de truste no âmbito internacional; para isso, utiliza uma abordagem dedutiva, a partir de um plano de fundo sistêmico-complexo. Busca-se desenvolver, ainda, reflexões acerca da possibilidade de uma regulação democrática que tenha o condão de evitar abusos desses gigantes da internet.
\end{abstract}

Palavras-chave: Brasil; gigantes da internet; práticas anticoncorrenciais; poder; sociedade em rede.

\footnotetext{
O presente trabalho é derivado da apresentação realizada pela autora em 13 de dezembro de 2016 na Université Paris Descartes, no colóquio Propriété(s) et données. Os autores agradecem ao convite das organizadoras, professora Nathalie Marthial-Braz (Université Paris Descartes) e professora Célia Zolynski (Université de Versailles Saint-Quentin-en-Yvelines).

" Graduada em Direito pela Faculdade de Ciências Jurídicas e Sociais da Pontifícia Universidade Católica do Rio Grande do Sul, Porto Alegre, Brasil. Mestre em Integração Latino-Americana pela Universidade Federal de Santa Maria, Santa Maria, Brasil. Doutora em Direito pela Universidade do Vale do Rio dos Sinos (Unisinos), São Leopoldo, Brasil. Pós-doutora em Direito do Institut des Hautes Études sur la Justice (IHEJ), Paris, França. É coordenadora e professora do Departamento de Direito e do Programa de Pós-graduação em Direito da Universidade Federal de Santa Maria, Santa Maria, Brasil. Coordenadora do Centro de Ciências Jurídicas Comparadas, Internacionalização do Direito e Sistemas de Justiça da mesma universidade, inscrito no Conselho Nacional de Desenvolvimento Científico e Tecnológico (CNPq), Santa Maria, Brasil. E-mail: janiasaldanha@gmail.com

*.. Graduado em Direito pela Universidade Franciscana, Santa Maria, Brasil. Mestre em Direito pelo Programa de Pós-graduação em Direito na Universidade Federal de Santa Maria, Santa Maria, Brasil. Membro do grupo de pesquisa Núcleo de Direito Informacional da mesma universidade, inscrito no CNPq, Santa Maria, Brasil. E-mail: gphoffmeister@gmail.com

.... Graduanda em Direito na Universidade Federal de Santa Maria, Santa Maria, Brasil. Bolsista de iniciação científica no Programa Institucional de Bolsas de Iniciação Científica (Pibic-CNPq). Membro do Centro de Ciências Jurídicas Comparadas, Internacionalização do Direito e Sistemas de Justiça da Universidade Federal de Santa Maria, inscrito no CNPq, Santa Maria, Brasil. E-mail: clararossatto96@gmail.com
} 


\section{The anti-competitive practices of the internet giants corporations in the brazilian context}

\section{ABSTRACT}

The networked society promotes the use of information and communication technologies, especially the Internet. Large companies acting in this way establish themselves as real "giants" and determine new power dynamics and challenges to a democratic regulation of the Internet. The work seeks to map some anti-competitive practices of the "giants of the Internet" from the analysis of some decisions of the Administrative Council of Economic Defense in the Brazilian context and other bodies responsible for inhibiting trust practices in the international environment; for such, it uses a deductive approach, from a systemic-complex background plan. It also seeks to develop reflections on the possibility of a democratic regulation aimed at preventing abuses of these "Internet giants".

Keywords: Brazil; internet giants; anti-competitive practices; power; networked society.

\section{Las prácticas anticompetitivas de los gigantes del internet en el contexto brasileño}

\section{RESUMEN}

La sociedad en red potencia la utilización de las tecnologías de la información y comunicación, sobre todo el internet. Grandes empresas que actúan en ello se establecen como verdaderas "gigantes" y determinan nuevas dinámicas de poder y desafíos a una regulación democrática del internet. El trabajo busca mapear algunas prácticas anticompetitivas de los "gigantes del internet" desde el análisis de algunas decisiones del Consejo Administrativo de Defensa Económica en el contexto brasileño y de otros órganos responsables de cohibir prácticas de trust en el ámbito internacional; para tal, utiliza un enfoque deductivo, desde un plan de fondo sistémico-complejo. Se busca desarrollar reflexiones acerca de la posibilidad de una regulación democrática que tenga el objetivo de evitar abusos de estos "gigantes del internet".

Palabras clave: Brasil; gigantes del internet; prácticas anticompetitivas; poder; sociedad en red. 


\section{INTRODUCÃ̃O}

O presente artigo visa apresentar algu mas reflexões acerca da relação entre regulação da internet e o poder das empresas denominadas gigantes da internet ${ }^{1}$ para compreender a dinâmica organizacional da sociedade em rede. Esse é um antecedente necessário para otimizar a avaliação quanto à real possibilidade de efetivação de uma regulação democrática que evite práticas abusivas dessas gigantes no que tange ao direito concorrencial.

A expansão em qualidade e quantidade da utilização de computadores e da internet torna fundamental discutir quais os limites e os desafios que se apresentam à proteção de atores menores em face das gigantes que atuam no campo das novas tecnologias de informação e comunicação.

A dificuldade em garantir uma regulação concreta da internet é um dos desafios à consolidação de uma sociedade efetivamente democrática. De fato, a complexidade das relações que se estabelecem e que compõem o quadro da sociedade em rede exige uma análise jurídica que transcenda a esfera puramente dogmática.

Com efeito, o tema que será discutido se caracteriza pela sua dinamicidade, não

\footnotetext{
A expressão gigantes da internet será utilizada em referência à figura do gigante, clássico personagem de proporções colossais que, ao longo dos tempos, esteve sempre presente na literatura, ora de forma mais atrapalhada, ora de forma mais arguta.
}

linearidade, dialética evolutiva, intensidade e ambivalência. E, por reunir os mais variados interesses, está sujeito aos influxos do poder econômico e político. Reconhecer a complexidade do tema permitirá abordá-lo sem a pretensão de oferecer respostas definitivas ou exaustivas, objetivando-se apenas contribuir com notas reflexivas sobre como o Brasil tem decidido acerca da temática que envolve o direito concorrencial a partir da grande expansão da internet ${ }^{2}$.

Para cumprir esse objetivo, esta exposição está dividida em duas partes: na primeira, faz-se uma análise da importância das tecnologias de informação no contexto do mundo globalizado, de sua relação com o crescimento e expansão de empresas que dominam o mercado nessa área, hoje consideradas verdadeiras gigantes; finalmente, dos desafios de ordem estrutural necessários à regulação democrática nesse campo.

Na segunda parte, verifica-se o estado da questão acerca das práticas anticoncorrenciais das gigantes da internet no mundo, em razão do exercício de poder e das relações econômicas no quadro da sociedade em rede. Ao final, o foco de análise é o contexto brasileiro, cujo objetivo é contribuir com o diálogo internacional na busca de soluções para essa questão tão importante na atualidade.

\footnotetext{
2 Sobre a abordagem complexa, pode-se consultar Morin (2003, p. 8).
} 


\section{UM CENÁRIO TECNOLIBERAL: O PODER DAS GIGANTES DA INTERNET E OS DESAFIOS Ȧ REGULAMENTACÃO DEMOCRÁTICA NO CONTEXTO GLOBÁL}

A humanidade do século XX conheceu uma alteração significativa nos processos de desenvolvimento tecnológico, econômico, cultural, histórico, jurídico, político e social. Esses processos, somados, desenharam paulatinamente um outro tipo de sociedade nomeada, por Manuel Castells (2007), de "sociedade em rede", na qual a internet assumiu um papel de centralidade. Entretanto, é necessário dizer que, na reta final da segunda década do século XXI, a internet é apenas uma parte do ambiente informacional.

De fato, o tempo da "idade do acesso" (Sadin, 2016, p. 29) por meio das telas dos computadores, que caracterizou o "momento internet", representado pelas comunicações virtuais que, ao longo de algumas décadas, massificaram-se, fez emergir o protagonismo das novas tecnologias da informação e comunicação (TIC) que, como é sabido, não cessa de se intensificar. Mas, ao lado dessa era, surge outra de forma inconteste. Trata-se da "era da medida da vida" (Sadin, 2016, p. 29). A gestão de dados por meio do big data (Bourcier e De Filippi, 2016), o controle algorítmico da vida humana e a organização massivamente automatizada das sociedades são três dimensões que caracterizam a profunda mudança ocorrida na natureza do mundo informacional.

Ao se assumir que o desenvolvimento das tecnologias da informação e comunicação são, ao mesmo tempo, causa e efeito de um novo modelo organizacional da sociedade - o da "economia dos dados" (Bourcier e De Filippi, 2016, p. 20) —, é preciso pensar no inevitável surgimento de interesses relativos ao controle dessas tecnologias porque representam um novo tipo de exercício de poder compreendido como "tecnoliberalismo". Seduzidos pelas soluções milagrosas prometidas pelo mundo das grandes empresas de TIC, os governos dos Estados, em diferentes partes do mundo, têm sucumbido à "economia dos dados" na esperança de antecipar o futuro e dar respostas - importantes do ponto de vista eleitoral — sobre temas que estão na ordem do dia, como o crescimento e o emprego. Então, os políticos surgem como os principais porta-estandartes do que Éric Sadin denomina de "silicolonização do mundo".

O tecnoliberalismo, longe de ser mera ficção ou expressão de mentes criativas, é a consequência mais imediata da absorção do público pelo privado que comprova a estreita simbiose entre a técnica, a economia e a política, cujo resultado mais tocante é o triunfo econômico de empresas que exercem poder sobre vários âmbitos da vida humana e impõem a mercantilização da vida a partir de seus próprios interesses (Sadin, 2016, p. 32).

Para garantir o exercício de poder, essas empresas, que assumiram uma posição de destaque no oferecimento de produtos e serviços no alvorecer do processo de crescimento da internet, acabaram se tornando verdadeiras gigantes. Juntamente do poder econômico decorrente de seu 
crescimento, adveio, por conseguinte, o poder político e, com ele, a capacidade de influenciar a regulamentação do mundo virtual no âmbito dos Estados e de suas jurisdições.

O presente capítulo objetiva, em um primeiro momento (1.1), fazer um panorama do atual estado de coisas da sociedade em rede, a fim de explicar o contexto em que surgiram e se desenvolvem as gigantes da internet e o processo pelo qual se deu o seu acúmulo de poder. Em um segundo momento (1.2), busca-se verificar os desafios que se colocam a uma regulamentação democrática da internet, no contexto global, tendo em vista os interesses e o poder político e econômico exercido pelas gigantes da internet.

\subsection{A configuração das relações de poder das gigantes da internet na atualidade}

Não há dúvida de que o alvorecer do século XXI se configura como um período histórico absolutamente diverso de qualquer outro observado até então. A sociedade em rede é causa e efeito de diversas alterações nas dinâmicas relacionais em todo o mundo. Na proporção direta da perda de protagonismo dos Estados para determinar os modelos de sociedades sob a perspectiva econômica e política, ocorreu o agigantamento de algumas empresas que, se do ponto de vista de sua origem jurídica e administrativa estão estabelecidas em um ponto preciso do planeta — o Vale do Silício são desterritorializadas em razão de sua larga atuação global.
É evidente que entre essas causas e efeitos, a desterritorialização pode ser assumida como um deslocamento profundo do "terreno" onde ocorrem as relações de poder (Castells, 2015, p. 96). Ora, o fim do "nacionalismo metodológico", de que falou Ulrich Beck (2002), em razão do aparecimento de atores concorrenciais aos Estados na cena internacional, já não é mais nenhuma novidade. No entanto, ajuda a explicar o lugar central que assumiram determinados atores privados na agenda das relações internacionais e das políticas estatais, como é o caso das grandes empresas transnacionais de informação e comunicação.

Se o poder é a capacidade relacional que permite a um ator social influenciar assimetricamente as decisões de outros atores sociais de forma a favorecer a vontade, os interesses e valores do ator que detém o poder, as novas formas de governabilidade antevistas por Foucault e instauradas pelas tecnologias de comunicação e informação são a prova hoje dessa assimetria por exercerem um enorme poder de influência sobre a vontade humana, que é, cada vez mais, reduzida à força dos protocolos automatizados das empresas, à engenharia organizacional e à orientação robotizada dos gestos humanos.

Nesse sentido, os Estados, que tradicionalmente representaram a manifestação do exercício de poder, porquanto atores primeiros a envolver-se em relações destinadas a exercer dominação sobre os sujeitos, antes de serem confrontados com a nova economia informacional, são seus 
ávidos consumidores. Esse relacionamento entre poder público e poder privado, que deu origem ao "tecnoliberalismo", é a prova cabal de que o mundo informacional não existe como um ser separado. Ele não apenas alterou profundamente as condições de atuação estatal, mas também determinou o predomínio dos interesses das indústrias dirigidas ao lucro a qualquer preço sobre os interesses das pesquisas científicas.

Por isso, pode-se facilmente constatar que o poder das grandes empresas de TIC não é neutro. Ele não constitui um atributo em si mesmo, na medida em que se manifesta sempre no âmbito relacional entre atores sociais e estabelece processos assimétricos de governabilidade. Tais processos prescindem da faculdade de julgamento e de ação porque neutralizam a consciência e a espontaneidade humana, razão pela qual inauguram novos tipos de totalitarismos muito mais fortes do que as meras restrições da liberdade, como tão bem identificou Hannah Arendt (2002, pp. 190-191).

O localismo globalizado (Santos, 2006, p. 438) nascido na linha do "horizonte radiante do Pacífico" (Sadin, 2016, p. 19) e na terra da Califórnia, o antigo estado do "ouro" americano, convertido no "estado do silício", desenha a "nova América" do século XXI não apenas territorializada, mas, antes, detentora de um espírito desterritorializado, ou seja, o do "Vale do Silício" (Sadin, 2016, p. 21). As vitórias sucessivas das grandes empresas de TIC são a prova evidente do sucesso empresarial e industrial na presente época e que, por meio delas, assumiu uma posição dominante sobre o mercado global, percebida no aumento de sua capacidade de exercício de poder. Nesse contexto, alguns atores que sequer existiram antes do advento da internet - como é o caso da Apple, Google, Facebook, Cisco, Netflix, Instagram, Twitter, Intel, por exemplo - gozam de uma posição de elevado destaque no quadro da sociedade em rede.

É preciso levar em conta, ao mesmo tempo, que, no processo de cristalização das relações de poder, atores moldam instituições na medida de suas possibilidades ao mesmo tempo que são moldados por elas (Giddens, 2009). Assim, à medida que a estrutura organizacional da sociedade se altera, sobretudo quando se modificam também as formas de sociabilidade e a influência política e econômica dos atores envolvidos no processo, a alteração das relações de poder é uma consequência inevitável do processo.

Um ranking publicado pela revista Fortune (Gandel, 2016) aponta para quatro grandes empresas no ramo dos computadores e da internet entre as cinco mais valiosas e rentáveis no mercado mundial: Apple, Alphabet (conglomerado empresário que é proprietário da Google), Microsoft e Facebook. Para se ter uma dimensão do que isso representa economicamente, os lucros dessas empresas superam o Produto Interno Bruto de mais de uma centena de países no ano de 2015, segundo os rankings do Banco Mundial, do Fundo Monetário Internacional e da Organização das Nações Unidas. 
A Google Inc., por exemplo, desde a sua fundação em 1998 (Google, 2014)³, cresceu em proporções absolutamente extraordinárias (Statista, 2016) ${ }^{4}$ e expandiu o seu domínio para muito além do motor de buscas. Outros softwares da empresa como o editor de fotos Picasa, a antiga rede social Orkut, a plataforma de e-mail Gmail, o navegador Google Chrome, além da liderança no desenvolvimento do sistema operacional Android, colocam a Google entre as maiores.

Em outras palavras, algumas empresas do ramo da internet se tornaram verdadeiras gigantes. Porém, se em Cervantes os "gigantes" não passavam de inofensivos moinhos de vento, as empresas que são chamadas de gigantes no atual contexto da internet não são caracterizadas pela inofensividade. Ao contrário, a sua marca é justamente um sofisticado domínio tecnológico capaz de projetá-las entre as companhias não apenas mais valiosas do planeta, mas também mais poderosas em razão de um específico saber-poder que aspira "pilotar" o curso da vida humana (Sadin, 2016, p. 114).

A percepção de Steve Jobs de que era necessário investir mais sobre o "meio ambiente" e sobre a relação "homem-má-

3 Andy Bechtolsheim assina um cheque de 100 mil dólares para uma entidade que ainda não existe: uma empresa chamada Google Inc.

4 De acordo com o website Statista, enquanto os ganhos com publicidade da Google giraram em torno de 400 mil dólares no ano de 2002, no ano de 2016, os lucros com o mesmo setor ultrapassaram a casa dos 74,5 bilhões de dólares. Além disso, o valor de mercado da empresa está acima de 373 bilhões de dólares. quina" deu origem às máquinas intuitivas criadas pela Apple Inc. e representadas não apenas numa cadeia de hardwares, da qual são exemplos o Macintosh, o Ipod, o iPhone, o iPad, a Apple TV, o Apple Watch, quanto nos softwares que lhes são embutidos, como os sistemas operacionais iOS, para dispositivos móveis, o navegador de mídia iTunes, o navegador Safari, entre outros. A Microsoft Corporation também fabrica, licencia, desenvolve, apoia e vende softwares de computador, produtos eletrônicos, computadores e serviços pessoais.

Além dessas, outros gigantes da internet como o Facebook, a rede social mais utilizada do mundo, e a Amazon, empresa transnacional de comércio eletrônico nos Estados Unidos, despontam como destaque no ramo de negócios virtuais.

A razão do agigantamento das empresas que têm se destacado no setor de computadores e internet é, conforme já evidenciado, o fato de serem as responsáveis pelo aperfeiçoamento tecnológico e informacional que caracteriza - e possibilita - a alteração dos padrões de sociabilidade humana e a reorganização da sociedade numa organização em rede (Castells, 2015) ${ }^{5}$. Nesse quadro, a utilização de TIC potencializa esse processamento, como é o caso do uso dos algoritmos ou do big data. Elas são programadas e, ao mesmo

5 Rede é um conjunto de nós interconectados, na qual os mais importantes são chamados de centros. Na sociedade em rede, a importância dos nós é diretamente proporcional à capacidade de absorver informações mais relevantes e de processá-las de maneira mais eficiente (Castells, 2015). 
tempo, autoconfiguráveis (Castells, 2015, p. 67). Sua estrutura evolui de acordo com a capacidade da rede de se autoconfigurar em uma busca permanente por combinações de redes mais eficientes. O resultado é a consolidação de diversas redes mundiais globais que operam simultaneamente, ancoradas no paradigma da aceleração do ritmo da vida, da vida cotidiana e da técnica, para lembrar Artmut Rosa (2010).

A grande novidade é a transferência dessa lógica claramente perceptível no âmbito tecnológico informático para as demais estruturas sociais. Características de redes informacionais digitais - como a flexibilidade, a escalabilidade e a capacidade de sobrevivência - são perceptíveis no século XXI, também na forma de organização adotada pelos Estados em sua interação com outros atores que ganham projeção nesse novo cenário, em uma perspectiva interativa e globalizada.

É preciso ter em mente, porém, que o fenômeno de mundialização a partir da manifestação de redes globais não representa a evolução ou o aperfeiçoamento humano, mas apenas um novo modelo de sociabilidade que resulta do incremento capitalista provocado pela tecnologia. É em virtude dessa alteração que ocorre o deslocamento do terreno onde são produzidas as relações de poder. O ciberespaço ou "espaço-tempo cibernético" (Virilio, 1996, p. 122) assume a condição de um sexto continente desespacializado.

Diante desse rearranjo e deslocamento observado em relação à potencialidade do exercício de poder, fruto da sobre- posição de redes globais que diluem as tradicionais fronteiras do Estado-nação, é necessário refletir acerca dos limites que se colocam a uma regulamentação democrática de demandas que se apresentam no quadro de uma sociedade em rede global.

\subsection{Os Desafios à Regulamentação Democrática no Contexto Global}

Essa parte do trabalho visa mapear alguns dos desafios que se colocam a uma regulamentação efetivamente democrática da internet, dado que resta evidenciado o grande poder político e econômico exercido pelos gigantes que, em grande medida, a controlam. Devido ao fato de a internet se desenvolver em uma dimensão mundial, os desafios que se colocam à sua regulamentação assumem contornos que devem ser igualmente pensados a partir de uma perspectiva global.

Desse ponto, é possível elencar desafios para a regulamentação da internet que podem ser separados em cinco níveis: (1) a possibilidade de os Estados regularem uma área fortemente permeada pelo paradigma da aceleração e que não conhece limites tecnológicos, espaciais e temporais; (2) a partir de sua regulação, a forma a qual se dará o alinhamento com outros Estados; (3) o suporte da internormatividade advinda da soft law, por meio da qual atuam os gigantes, uma vez que são feitas à revelia dos legisladores nacionais; (4) a regulação de uma área em que os gigantes do setor adquiriram poder econômico tal a ponto de exercer uma influência enorme por sobre pratica- 
mente todos os domínios da vida social, inclusive os relativos à regulação, e (5) as implicações éticas e democráticas que se refletem nesse processo.

Quanto à primeira questão, como se pode observar na primeira parte do capítulo, o nacionalismo metodológico foi corretamente contestado por Ulrich Beck, uma vez que a globalização redefiniu substancialmente os limites territoriais do exercício de poder. No quadro da sociedade em rede, o global supera o local. Em uma "arquitetura digital cosmopolita" (Beck, 2013, p. 32), atrelada ao paradigma da aceleração e na perspectiva do espaço-tempo, verifica-se a evidente diluição dessas categorias no plano do ciberespaço.

Em outras palavras, o primeiro desafio à regulação da internet é decorrência direta do efeito da aceleração operada pela nova dinâmica advinda com a globalização, através das TIC. Ao mesmo tempo, a aceleração provocada por essas tecnologias se institui enquanto uma nova forma de totalitarismo e como produtora de uma profunda alienação.

Totalitarismo porque se constitui em um princípio abstrato que (1) exerce pressão sobre as vontades e ações dos sujeitos; (2) dele não se pode escapar, ou seja, afeta a todos; (3) é onipresente, porquanto se estende a todos os aspectos da vida social e (4) é difícil de criticar ou de combater. E alienação que se expressa em cinco dimensões: (1) em relação ao espaço; (2) em relação às coisas; (3) em relação às ações; (4) em relação ao tempo e (5) em relação aos outros (Saldanha, 2013, pp. 183-184).
É nesse campo em que a regulação da internet tem de operar. Impossível, portanto, não se deparar com as dificuldades que derivam de uma estrutura sujeita à lógica acelerada e ao desenvolvimento tecnológico constante. A internet é, por excelência, aberta, internacional, múltipla e possui uma arquitetura própria ${ }^{6}$. O que se constata, por muitas vezes, é uma atual impossibilidade material de resguardar certos direitos que perpassam por ela e regular ela própria — satisfatoriamente.

Assim, à medida que as novas tecnologias vão se desenvolvendo, é necessário que o Estado se ocupe de atualizar a legislação a fim de resguardar a proteção de direitos e de regular a internet. Até o momento, a legislação que melhor se enquadra à regulamentação da internet no contexto brasileiro é a Lei 12.965/2014, o Marco Civil da Internet (Brasil, 2014).

A aposta brasileira foi a de investir em uma legislação forte em princípios, uma vez que é difícil regulamentar uma área que se altera tão rapidamente, sobretudo em razão do desenvolvimento de tecnologias cada vez mais sofisticadas e inovadoras. Ainda assim, é impossível não

6 A arquitetura da rede, por exemplo, é responsável pela forma como o controle é exercido na web. Diferentes arquiteturas de sistemas exercem diferentes efeitos nas taxas e na concentração da inovação. Ainda que, enquanto em uma arquitetura baseada em um núcleo central de controle (core-centred architecture), os operadores da rede possuam poder para controlar alguns setores e algumas tecnologias que prevalecerão em face de outras, em uma arquitetura sem um núcleo central de controle (end-to-end architecture), como no caso brasileiro, as dinâmicas são muito mais diversificadas e incertas. 
verificar uma grande dificuldade quando o tema é pensado de uma perspectiva internacional. Como efetivar direitos relacionados à internet no Brasil, se, para que o ciberespaço brasileiro seja democrático, é preciso que seja acessível de qualquer lugar do planeta?

Quanto ao segundo ponto, é preciso pensar em um alinhamento entre Estados que permita regular o campo cibernético de forma efetiva no plano internacional. Nesse sentido, parece oportuno repensar o princípio de "um ou outro" a partir do cosmopolitismo metodológico e orientar as reflexões a partir de uma ótica inclusiva (Beck, 2013, p. 19). É necessário incorporar a noção de oposições inclusivas à racionalidade regulatória de temas eminentemente internacionais como a internet, rejeitando-se a ideia de oposições exclusivas.

Stefano Rodotà fala sobre uma substituição da globalização através dos mercados por uma globalização através dos direitos (Rodotà, 2008 , p. 6). Desde modo, o estabelecimento de tratados internacionais que se preocupem com o que o autor chamou de "constitucionalização da pessoa" pode ser uma solução factível para os problemas advindos das novas tecnologias.

Nesse quadro, ao invés de dar respostas que regulamentem especificamente a internet, como a Carta dos Direitos Fundamentais da União Europeia, o velho continente seria capaz de responder, caso a caso, às demandas de uma área que se altera tão rapidamente através da proteção da pessoa. Para Rodotà, não se trata de "impor" um modelo de proteção ao mundo, mas não se pode ceder a um multiculturalismo regressivo que justifique qualquer coisa em nome de tradições e normas locais. Para o autor, não é motivo para vergonha a pretensão universalista de um apelo aos direitos fundamentais, quando estão em jogo a vida e a dignidade das pessoas (Rodotà, 2008, p. 6).

Assim, no que tange especificamente à internet, Rodotà propõe uma compreensão dessa tecnologia como um bem comum, uma vez que compreende nessa categoria direitos ligados a direitos fundamentais, como o livre desenvolvimento da personalidade ou o acesso ao conhecimento (Rodotà, 2015). Alguns bens assumem uma importância de dimensão tamanha para a humanidade que já não podem (ou poderiam) ser regulados por apenas um ou outro ator. Dessa forma, é necessário que a internet seja regulada com a maior participação possível, a fim de concretizar uma regulamentação democrática $^{7}$ que responda aos anseios de um maior número de pessoas ao redor d o mundo.

Ainda no que diz respeito à cooperação entre os Estados com intuito de melhor regular a internet, uma contribuição fundamental vem do trabalho de Mireille Delmas-Marty. Prescrever regras com noções

\footnotetext{
Uma iniciativa que merece destaque, nesse sentido, é a Declaração Aberta sobre os Serviços Públicos aprovada na Conferência Ministerial Europeia de Governo Eletrônico. O documento foi produzido de forma colaborativa com a participação da sociedade civil europeia, em que foram afirmados alguns princípios sobre a matéria, como a transparência, a participação e a delegação de poder.
} 
indeterminadas pode ser um caminho a fim de melhor regulamentar uma área que se altera de forma tão veloz. Porém, noções indeterminadas não são noções indetermináveis. A proposta é a da substituição de uma pretensão regulatória absoluta por uma "colocação de setas" (Delmas-Marty, 2004, p. 122) que indique aos intérpretes que caminhos seguir, sobretudo com a proteção dos direitos humanos como farol.

Ainda nesse sentido, uma vez que a dispersão e a multiplicidade normativas são uma realidade incontrastável dos tempos atuais, as inúmeras fontes de produção do Direito nacionais e não nacionais convocam o intérprete a reconhecer tal dispersão e, no passo seguinte, perguntar-se sobre a necessidade de estabelecer-se ordenação ao múltiplo. A escassez de um mínimo de ordem conduz inevitavelmente à experiência do caos e aumenta os patamares de incerteza. Não fosse a alta complexidade que esse cenário apresenta, mais grave se mostraria essa realidade quando o que está em jogo é a aplicação e a efetivação de regras protetivas de direitos humanos (Saldanha, 2016, p. 147).

Apenas a título exemplificativo, faz-se referência à margem nacional de apreciação a qual se caracteriza como uma forma de buscar um comum universalista e pluralista, através da harmonização do múltiplo por meio de uma lógica da compatibilidade (Saldanha, 2016, p. 167). Ademais, em que pesem as dificuldades observadas em alguns casos, destaca-se que a margem nacional de apreciação "é uma das chaves do pluralismo ordenado e um importante mecanismo da construção do comum, que não rejeita a diversidade dos sistemas de direito e das culturas" (Saldanha, 2016, p. 167).

Como se as disparidades entre legislações jurídicas já não fosse problema suficiente, um terceiro desafio que se apresenta à regulação da internet é a existência de uma internormatividade advinda da soft law. Isso significa dizer que há um mundo paralelo de normas, por vezes desconhecido e estranho, mas que existe. Um mundo que, em diversos momentos, orienta e domina nossas vidas. Trata-se da regulação que não é produzida pelos atores tradicionais, como os Estados, nem por meio de seus legisladores, mas pelos novos atores que circulam na complexidade da(s) globalização(ões). A essas regulações que derivam de atores não tradicionais - que ocorrem frequentemente no campo da internet - , Benoit Frydman nomeou "ONNI - Objetos Normativos não Identificados" (Frydman, 2016).

Percebe-se, no século XXI, uma sofisticação dos processos de procedimentalização iniciados no século XX. Trata-se da erupção de "normas procedimentais" que visam responder às exigências das organizações, o que caracteriza a vitória da performatividade sobre as regras tradicionais, isto é, a vitória dos aspectos organizacionais sobre os aspectos jurídicos (Saldanha, 2014). Esse movimento coloca as clássicas regras jurídicas em concorrência com outros tipos de normas, quais sejam, as técnicas e as de gestão — ONNI — produzidas por experts. 
Com efeito, essas normas de dupla face - técnicas e de gestão - ocupam um lugar ainda pouco explorado pelos juristas. Dessarte, as concepções clássicas do direito são insuficientes para explicar essa transição dos aparelhos institucionais para fazer a mediação entre o que é produzido pela "expertise" dos laboratórios, pelas reuniões dos especialistas e pelos parlamentos nacionais e não nacionais (Saldanha, 2014). Isto é, mais uma vez se reforça a necessidade de alterar o olhar por sobre os problemas; transitar por esse tipo de dilema com uma perspectiva cosmopolita parece ser o melhor caminho para responder satisfatoriamente às demandas vinculadas à internet.

O expert pode ser entendido como um mediador, a pessoa apta a traduzir de forma imparcial um conhecimento hermeticamente fechado a poucos especialistas. Em outras palavras, alguém que combina a capacidade pessoal de compreender com o poder da ciência de apontar soluções a partir de decisões corretas (Bauman, 1999b, p. 209). Em outras palavras, o expert é o especialista em quem se pode confiar (Giddens, 1991). Isso representa um problema para os ordenamentos jurídicos, porque o que pode parecer neutro pode se revestir de interesses escusos às ordens democráticas.

É possível afirmar que a adoção dos ONNI não seria um problema se, apesar deles, o poder judiciário não ficasse privado da preocupação com a qualidade de suas decisões e sobre a necessidade de que sejam adequadas à Constituição. O predomínio de padrões, de normas técnicas e de gestão nos domínios do Poder Judiciário se, em aparência, parece envolver uma linguagem neutra, implica, profundamente, uma escolha valorativa que modifica imensamente o próprio sentido da justiça (Saldanha, 2014).

Outro grande problema da submissão aos padrões reside no fato de esse modelo de regulamentação agravar ainda mais — ao menos potencialmente — o déficit democrático. Mesmo nos países em que os parlamentos são fortes, há, em certa medida, uma forte pressão exercida por grupos de interesse que se estabelecem principalmente em razão do poder econômico. Em uma esfera como a internet, em que os experts são os que definem a regulação, é difícil pensar que a força principal não venha quase que exclusivamente do poder econômico dos atores envolvidos. Nesse processo, grandes corporações assumem o protagonismo desde a retaguarda, visto que os experts que propõem os ONNI são, muitas vezes, profissionais a serviço dos gigantes.

Essa reflexão remete ao quarto desafio, qual seja, o desafio diante do poder político e econômico exercido pelos gigantes da internet diante de praticamente todas as esferas da vida. As corporações assumem o protagonismo de um dos principais vedores da globalização: a economia capitalista mundial (Giddens, 1991, pp. 83-84). A construção de um Estado que se pretenda democrático e de direito perpassa pela reflexão acerca das dinâmicas de poder e dos limites ao seu exercício e manifestação. 
Se os fluxos mais importantes da atualidade — informação e capital — perpassam pela internet, não é por acaso que o mapeamento deles é constantemente vigiado, controlado e armazenado por empresas privadas e pelos Estados. Disso resulta ainda um controle perfeito, principalmente por parte dos Estados, os quais também se servem de informações e dados colhidos pelas empresas privadas (Saldanha, 2013, p. 212).

Isto é, ao mesmo tempo que urge uma maior e melhor regulação da internet, a qual se daria por meio dos Estados atores tradicionalmente responsáveis por limitar interesses privados em prol da coletividade — , estes restam submissos ao poder dos gigantes da internet, uma vez que necessitam das tecnologias e do processamento informacional dessas empresas. Trata-se de um novo momento de expropriação por parte do mercado, dessa vez em relação aos Estados, e que tem consequências terríveis para toda a sociedade (Bauman, 1999a, pp. 73-77).

De acordo com Supiot, "justiça social e mercado total" são ideias que não combinam. Quando o mercado se torna o principal responsável pela regulação das relações humanas, é difícil assegurar direitos à maior parte da população. Para Supiot, é necessário transcender a lógica de mercado por uma ética amparada na ideia de círculos de solidariedade, os quais seriam capazes de melhor garantir a proteção de direitos sociais (Supiot, 2014).

Por fim, o último desafio diz respeito às implicações éticas e democráticas que se refletem no processo regulatório da internet. É claro que todos os desafios se intercruzam, e as questões ética e democrática são uma decorrência de todas as outras exploradas até aqui. Assim, uma vez evidenciado o grande poder exercido pelos gigantes e sua capacidade de influenciar de forma tão incisiva no processo regulatório, resta a preocupação com os limites e as possibilidades de se operar uma regulação que privilegie uma ordem verdadeiramente democrática em detrimento de interesses privados.

O fato de a lógica econômica e empresarial sobrepujar a tradicional forma política democrática legislativa - através da influência econômica nos processos decisórios políticos - representa uma fragilização da proteção e efetivação de direitos e do potencial exercício de uma jurisdição que se pretenda justa. Uma vez que são grandes empresas multinacionais que se enquadram na categoria de gigantes da internet, a caracterização desses conglomerados, como grupos de interesse capazes de influenciar na tomada de decisões políticas, representa um motivo de preocupação para o mundo todo.

Na linha do que já foi demonstrado ao longo do texto, muitos dos países que restam sujeitos às interconexões de uma sociedade que se organiza em rede ficam vulneráveis ante decisões que são fortemente influenciadas por empresas que detêm um grande capital econômico e político. Significa dizer que os gigantes da internet são mais influentes que dezenas de países em desenvolvimento. Ao mesmo tempo, em países economicamente 
desenvolvidos, diversas populações que representam minorias restam sujeitas às decisões que são fortemente permeadas pelos interesses dos gigantes.

Ainda que possa parecer desolador, talvez todos esses desafios - ao mesmo tempo que apontam riscos dignos de preocupação - sejam capazes de superar os limites existentes à regulação da internet. Na esteira do pensamento de Beck, "a sociedade de risco produz novas oposições de interesse e um novo tipo de solidariedade diante da ameaça", ademais, há em si "uma dinâmica evolutiva de base democrática que ultrapassa fronteiras, através da qual a humanidade é forçada a se congregar na situação unitária das autoameaças civilizacionais"8 (Beck, 2013, p. 57).

Diante das reflexões apresentadas, o presente capítulo demonstrou, em um primeiro momento, o contexto em que surgiram e se desenvolvem os gigantes da internet e o processo pelo qual se deu o seu acúmulo de poder. E, em um segundo momento, apresentou alguns dos desafios que se colocam a uma regulamentação efetivamente democrática da internet, no contexto global, tendo em vista os interesses e o poder político e econômico exercido pelos gigantes da internet.

\section{UM CENÁRIO ANTICONCORRENCIAL DOS GIGANTES DA INTERNET: ANÁLISE DE CASOS CONCRETOS}

"Diante das enormidades, não há humanidade possível"9 é uma afirmação que

8 Grifado pelo autor no original.

9 Nós agradecemos ao professor Jorge Luis da Cunha, do Programa de Pós-graduação em encontra fundamento na mitologia grega. Titã, do grego Tıนóv, significa enormidade, ou seja, tudo aquilo que é tão grande que não pode ser apreendido pelos sentidos humanos e, portanto, não pode ser conhecido. Assim, quando o mundo é habitado pelos titãs, a humanidade não existe. O mais terrível e perverso dos titãs é Cronos — senhor do tempo - que, destronando seu pai, Urano, torna-se rei dos titãs. Casado com Réia, tem com ela seis filhos. Advertido por uma profecia de que um de seus filhos o destruiria, Cronos passa a devorá-los assim que nascem. Zeus, um dos filhos de Cronos, é salvo por sua mãe e entregue às Ninfas para crescer na Terra. Nela, vive a experiência sensível que aproxima sua existência titânica da experiência que dará origem à humanidade: o conhecimento (experiência sensível, significação subjetiva, ação objetiva). Adulto, Zeus conhece sua história e organiza com outros titãs e criaturas uma batalha contra Cronos que dura uma eternidade. A enormidade titânica de Cronos é derrotada por uma estratégia não titânica, fruto da experiência sensível e significada ao longo da vida de Zeus na Terra. Afastada a enormidade deste mundo, surge a humanidade! Humanidade que se mantém apenas na luta eterna contra o retorno dos titãs.

Assim, diante de toda a complexidade que marca o quadro da sociedade em rede e dos desafios que manifestam ante o poder dos gigantes da internet, as ordens jurídicas não podem se furtar a dar respostas aos casos concretos que

Educação, da Universidade Federal de Santa Maria, pelas valiosas ideias sobre esse tema. 
se apresentam aos tribunais. O segundo capítulo visa mapear, em uma primeira abordagem, algumas das práticas anticoncorrenciais praticadas pelos gigantes no contexto internacional; em uma segunda abordagem, os processos administrativos instaurados pela superintendência-geral do Conselho Administrativo de Defesa Econômica (Cade) e a incidência do Marco Civil da Internet no Brasil.

\subsection{As Práticas Anticoncorrenciais dos Gigantes da Internet no Contexto Internacional}

Em razão de o poderio de serviços on-line estar cada vez mais concentrado nas mãos desses gigantes, os abusos que envolvem a anticoncorrência passam a ser mais frequentes, e os entraves advindos dessas práticas transcendem as margens fronteiriças; trata-se de empresas transnacionais que discutem um domínio tecnológico de âmbito global.

Recentemente, a Google Inc., que tem como principal fonte de lucro a publicidade por AdWords em seu mecanismo de buscas, foi alvo de investigações perante a Comissão Europeia (CE), a Federal Trade Comission (FTC), nos Estados Unidos, e o Cade, no Brasil, por favorecer seus próprios produtos nos resultados de busca em detrimento dos rivais. Em nota (European, 2016) divulgada em 14 de julho de 2016, a CE informa a Google de duas conclusões preliminares da investigação iniciada contra a empresa em meados de 2010. A primeira, de que a companhia abusou de sua posição dominante ao favorecer sistematicamente o seu serviço na comparação de compras em suas páginas de resultados de pesquisa; a segunda, de restringir artificialmente a possibilidade de outros sites exibirem anúncios de concorrentes da Google no seu mecanismo de busca.

Em investigação semelhante, finalizada pela FTC em janeiro de 2013, as conclusões foram diferentes. Para a FTC, não houve prejuízos à livre competição na manipulação dos resultados de buscas pelo Google, e as mudanças dos algoritmos que estão sendo alegadas de causar desvantagens aos concorrentes podem, plausivelmente, serem vistas como uma melhoria na qualidade geral das pesquisas Google (FTC, 2013).

Contudo, em junho de 2017, a investigação pela CE restou concluída, e a Google foi condenada a pagar uma multa de 2,42 bilhões de euros, o equivalente a 8,97 bilhões de reais. Apesar de a condenação pela entidade ter sido esperada em razão de suas prévias declarações feitas à imprensa quanto aos rumos da investigação (Vieira, 2017), o valor da multa impressionou — foi a maior condenação da história que envolveu gigantes da internet. A comissária Margrethe Vestager, responsável pela política da concorrência, declarou:

A Google tem criado muitos produtos e serviços inovadores que mudaram as nossas vidas, o que é uma boa coisa! Porém, a estratégia da Google para o seu serviço de comparação de preços não era apenas a de atrair clientes tornando o seu produto melhor do que o dos seus concorrentes. Em vez disso, a Google abusou da sua posição dominante no 
mercado na vertente de motor de busca, promovendo o seu próprio serviço de comparação de preços nos seus resultados de pesquisa e despromovendo os dos concorrentes. (European, 2017, s/p)

Em nota oficial, a Google afirma que discorda da decisão e que:

Acreditamos que a decisão de compras on-line da Comissão Europeia subestima o valor desses tipos de conexões rápidas e fáceis. Embora alguns sites de compras de comparação esperem que o Google mostre mais proeminentes, nossos dados mostram aquilo que as pessoas geralmente preferem, e links que os levam diretamente aos produtos que as pessoas querem, e não aos sites onde eles devem repetir suas pesquisas. ${ }^{10}$ (Walker, 2017, s/p)

De toda sorte, além de pagar a multa, a Google teve de pôr termo a essa prática no prazo de 90 dias ou incorreria em sanções pecuniárias que poderiam representar até $5 \%$ do volume de negócios médio diário no contexto mundial da Alphabet, a empresa-mãe da Google.

Além disso, outro caso emblemático é a reclamação feita através de uma carta dirigida a alguns membros do Congresso Americano pela empresa sueca Spotify à americana Apple. O Spotify acusa a Apple de abusar de seu domínio sobre o sistema operacional iOS para diminuir a competição no serviço de música em streaming. O litígio se deve ao fato de a Apple cobrar uma taxa de 30\% das transações feitas

10 Tradução livre feita pelos autores. através da plataforma AppleStore, o que obriga o app Spotify a aumentar o preço da assinatura para custear a comissão da Apple. Essa taxa adicional já foi alvo de crítica no passado pela Amazon, que hoje disponibiliza somente uma versão limitada do seu aplicativo na App Store e, por conseguinte, interrompeu as vendas de Apple TV em suas lojas. O Spotify, por sua vez, passou a estimular os seus usuários a adquirirem o aplicativo fora da plataforma, e essa conduta serviu de pressuposto para a Apple rejeitar as novas versões do app Spotify para os seus aparelhos. Diz o vice-presidente sênior e conselheiro-geral da Apple, Bruce Sewell:

Logo após o Spotify enviar seu app em 26 de maio, nossa equipe identificou uma série de problemas, incluindo que o recurso de In-App Purchases tinha sido removido e substituído por um recurso de inscrições que claramente tinha o intuito de desviar das regras de divisão de lucros da Apple. [...] Em 10 de junho, o Spotify enviou outra versão do app, que, de novo, incorporava o sistema de inscrições, desta vez orientando os consumidores a digitar um endereço de email para que eles pudessem ser contatados diretamente pelo Spotify em uma tentativa continuada de evitar nossas guidelines (Santana, 2016, s/p).

Segundo Horacio Gutierrez, conselheiro-geral de advocacia do Spotify, a americana respondeu ao Spotify agressivamente, chegando, inclusive, a ameaçar retirar o utilitário da App Store. Assim, para não perder os usuários de iOS, a 
companhia teve que voltar atrás com a promoção. Entretanto, esses acontecimentos despertam dúvidas quanto aos reais motivos da resistência da americana. Afirma Gutierrez:

Este último episódio levanta
sérias preocupações sob as leis
de competitividade dos Estados
Unidos e da Europa. A Apple con-
tinua a excluir e diminuir a com-
petição do Spotify no iOS para
beneficiar o Apple Music, princi-
palmente quando analisamos o
histórico de condutas anticompe-
titivas da Apple contra o Spotify.
Nós não podemos nos manter
alheios enquanto a empresa usa
o processo de aprovação da App
Store como uma arma para ferir
os rivais. (Munhoz, 2016, s/p)

Embora esse contencioso ainda não tenha tido parecer de comissões que tratam de questões concorrenciais, é de suma relevância para o direito entender como têm agido os gigantes da internet entre si, e em que medida esses fechamentos dos sistemas podem ser danosos para uma rede que se postula inovadora. Um grande exemplo foi a condenação da CE a pagamento de multa no valor de 899 milhões de euros pela Microsoft, por desrespeito às regras antitruste do bloco europeu, em 2008 (EUR-LEX, 2008, s/p). O que motivou a decisão foram as cobranças abusivas feitas pela Microsoft pelo fornecimento de informações técnicas aos desenvolvedores para a criação de programas compatíveis com o sistema operacional Windows (pertencente à Microsoft). Se, somada às demais sanções impostas pelo mesmo órgão em 2004 (European,
2007, s/p), o valor cobrado alcançaria o montante de 2,7 bilhões de euros (TI Inside, 2008, s/p). Diz a Comissária Europeia da Concorrência Neelie Kroes sobre a decisão: "Espero que a decisão de hoje encerre um capítulo escuro no registro de não conformidade com a decisão da Comissão Europeia promulgada em março de 2004 e mantida em 2007 pelo Tribunal de Primeira Instância contra a Microsoft"ll (European, 2008, s/p).

Entretanto, os casos não se esgotam no ocidente do mundo. Em agosto de 2016, em sede de apelação ao órgão antitruste russo - Federal Antimonopoly Service of the Russian Federation (FAS) — a Google é condenada a pagar uma multa de 438 milhões de rublos (6,8 milhões de dólares) por instalar previamente aplicativos em aparelhos móveis que rodam seu sistema operacional Android, após uma reclamação da russa Yandex. A razão da penalidade se deve ao abuso de posição dominante que viola lei federal russa de proteção à competição (FAS, 2016, s/p).

No contexto internacional, portanto, pode-se verificar que os organismos antitrustes, especialmente os dos Estados Unidos e da União Europeia, ao investigarem o autofavorecimento no serviço de busca especializada desempenhado pelo buscador geral da Google, chegam a conclusões divergentes. Tais comportamentos explicam-se quando observados sob a perspectiva do direito comparado.

\footnotetext{
11 Tradução livre feita pelos autores.
} 
Se, no modelo americano, o direito à concorrência representa um princípio fundamental que justifica ações agressivas das empresas dominantes para ganhar mais vantagens competitivas (Fidelis, 2015, p. 180), na experiência europeia, o direito anticoncorrencial surge em um contexto de aproximação dos mercados e de manutenção do bem-estar social. Nesse caso, a tutela jurisdicional recai menos sobre a competição e mais sobre os consumidores.

\subsection{Os Processos Administrativos Instaurados pela Superintendência-geral do Cade e a Incidência do Marco Civil da Internet no Brasil}

Segundo o artigo $4^{\circ}$ da Lei $12.529 / 2011$ (Brasil, 2011), que estrutura o Sistema Brasileiro de Defesa da Concorrência (SBDC), o Cade ${ }^{12}$ constitui autarquia federal vinculada ao Ministério da Justiça, e é entidade judicante com jurisdição em todo o território nacional. Ao seu Tribunal Administrativo, importa julgar as infrações à ordem econômica e aplicar as sanções administrativas cabíveis, além de apreciar em grau recursal as medidas preventivas adotadas pelo Conselheiro-Relator ou pela Superintendência-geral. Embora esse órgão possua independência funcional, tem a obrigação de reprimir as infrações à ordem econômica, orientada pelos ditames constitucionais de liberdade de iniciativa, livre concorrência, função social da propriedade, valorização do trabalho humano, pleno emprego, defesa

12 Fazem parte do Cade os seguintes órgãos: Tribunal Administrativo de Defesa Econômica, Superintendência-geral e Departamento de Estudos Econômicos (art. 50, Lei 12.529/2011). dos consumidores e repressão ao abuso do poder econômico, entre outros (Brasil, 1988) $)^{13}$.

No que diz respeito aos gigantes da internet, em 2013, o Cade entendeu que houve indícios suficientes para a abertura de três processos administrativos contra a Google Inc.

Um primeiro, que visa apurar, via denúncia da E-Commerce Media Group Informação e Tecnologia Ltda, se o Google Shopping não estaria posicionando-se de maneira privilegiada entre os outros links patrocinados, além de, nos resultados de busca, favorecer-se perante outros concorrentes como o Buscapé e Bondfaro ${ }^{14}$ - pertencentes à E-Commerce. A investigação visa esclarecer, ainda, se o Google Buscas adotou mecanismos para reduzir o espaço da busca e também confundir o usuário na apresentação dos resultados. Ademais, o Cade intenta esclarecer a alegação de que o Google Buscas apresentou os anúncios com foto de seus sites temáticos de modo mais atrativo que os dos concorrentes e, também, sobre o Google ter se recusado a vender anúncio ao Buscapé e, depois, ter exigido dados concorrencialmente sensíveis para permiti-lo (Cade, 2011).

13 "A lei reprimirá o abuso do poder econômico que vise à dominação dos mercados, à eliminação da concorrência e ao aumento arbitrário dos lucros" (art. 173, § 4º, Constituição da República Federativa do Brasil).

14 O Buscapé e o Bondfaro são sites brasileiros que possuem o serviço gratuito de comparação de preços de diferentes produtos em diferentes lojas. 
Um segundo, também através de denúncia da E-Commerce, que pretende investigar suposta prática denominada de "scraping" (raspagem) pelo Google que é a apropriação indevida de reviews (opiniões dos clientes sobre qualidades ou defeitos de lojistas e produtos) — dos sites de comparação de preços Buscapé e Bondfaro. Ainda, segundo a empresa, essa prática de subtrair informações relevantes é unilateral, uma vez que o Google não permite que outras empresas façam raspagens de seus sites temáticos (Cade, 2013a).

E um terceiro, mediante denúncia da Microsoft Corporation, de o Google dificultar a interoperabilidade conhecida como multihoming - que é o gerenciamento simultâneo dos anunciantes de suas campanhas publicitárias na plataforma Google e em outras plataformas menores. No entanto, para isso ocorrer, requer-se o compartilhamento de informações que, segundo o denunciante, o Google recusou-se a fazer, desestimulando ainda mais o uso dos serviços de buscadores rivais (Cade, 2013b).

Além disso, mais recentemente, a Yelp, empresa multinacional norte-americana, que possui site voltado à avaliação de estabelecimentos comerciais, também alegou, perante o Cade, que o Google tem desviado o resultado de buscas para os seus próprios produtos (Cade, 2016). O Yelp, em uma petição inicial de quase 300 páginas, afirma que o Google tem usado uma caixa para posições de destaque em sua página de resultados - alimentada exclusivamente com links para o Google+
- ao passo que transfere retornos potencialmente mais relevantes para baixo.

Nesses processos, valeu-se do argumento de que as denúncias "são resultados da aplicação da política internacional do Google que, reiteradamente, tem se aproveitado de sua posição dominante no mercado mundial de 'busca on line' para, a partir de artifícios anticompetitivos, monopolizar também outros mercados verticalmente relacionados, prejudicando, desta forma, concorrentes, internautas e lojistas" (Cade, 2013b).

Embora ainda não haja decisões sobre os casos acima relatados, o Cade tem se valido de princípios constitucionais para decidir sobre outras matérias, o que serve para avaliar o perfil desse órgão antitruste. Em artigo que visa avaliar a defesa da concorrência e a concretização dos princípios da ordem econômica constitucional, os autores fizeram uma análise de julgados emblemáticos do Cade tanto na atuação preventiva como repressiva, e concluíram que a autarquia vem sim cumprindo sua missão (Fonseca e Carmo, 2013).

Um deles, no ramo alimentício, foi a fusão (Cade, 1997) das duas maiores empresas do setor de bebidas do Brasil, Antártica e Brahma, em AmBev - hoje a maior do mundo - , na qual a decisão de condicionar a aprovação da fusão a Termo de Compromisso de Desempenho demonstrou preocupação com a preservação dos postos de trabalho nas indústrias que seriam fundidas, bem como nas diversas empresas existentes na cadeia de 
distribuição e revenda. Outro, no setor automotivo, foi a autorização da aquisição pela Volkswagen de $55,90 \%$ da participação do capital social da MAN SE (Cade, 2007, pautada pela noção de desenvolvimento tecnológico, industrial e na viabilização da concretização de normas voltadas ao desenvolvimento econômico e industrial do Estado. Ainda outra decisão (Migalhas, 2016), que versava sobre o abuso de posição dominante da Unimed, a maior cooperativa de trabalho médico do mundo, a qual exigia exclusividade de seus cooperados; essa conduta, além de ferir a concorrência por reforçar o domínio de mercado da Unimed, violava o princípio da dignidade da pessoa humana, pois a esse consumidor - que necessitava de serviços médicos - , muitas vezes, era negado o acesso a profissional habilitado para prestar serviço essencial à vida; e o Cade foi responsável por barrar tais comportamentos.

Destarte, das decisões tomadas pelo tribunal antitruste brasileiro, pode-se chegar a duas conclusões. A primeira se refere a que, historicamente, o Cade tem resolvido questões que envolvem "gigantes" de outros tipos de mercado, o que demonstra que possui experiência de atuação em cenários jurídicos que implicam atores de grandes dimensões. A segunda, ao extrair-se o fundamento principal das suas decisões, pode-se afirmar que o Cade tem construído sua jurisprudência com base em princípios - como os ditames constitucionais já citados (liberdade de iniciativa, livre concorrência, função social da propriedade etc.) - além de elencar a "coletividade" como titular dos bens jurídicos protegidos pela lei que regula a sua atividade (art. 1, parágrafo único, Lei 12.529).

Como já mencionado, ainda não há decisões sobre os gigantes da internet para serem apresentadas neste trabalho. Entretanto, é possível que, a partir do histórico decisional do Cade, estabeleça-se a previsão - pelo caráter transcendental dos princípios - de que as suas decisões que envolvem as práticas anticoncorrenciais dos gigantes da internet tendem a ser motivadas por princípios previamente estabelecidos:

\begin{abstract}
Os princípios representam a introdução do mundo prático no direito. Neles se manifesta o caráter da transcendalidade. Em todo caso compreendido e interpretado já sempre aconteceram os princípios - e não o princípio; toda decisão deve ser sempre justificada na comum-unidade dos princípios, como nos mostra Dworkin. (Oliveira, 2007, p. 204)
\end{abstract}

No que diz respeito ao Marco Civil da Internet, implementado a partir da Lei 12.965/2014, e recentemente regularizado pelo Decreto Presidencial 8.771/2016 (Brasil, 2016), ficou estabelecido que "a apuração de infrações à ordem econômica ficará a cargo do Sistema Brasileiro de Defesa da Concorrência, nos termos da Lei n. 12.529 , de 30 de novembro de $2011 "$ (art. 19, Decreto 8.771/2016). Ademais, no artigo $9^{\circ}$ do Decreto, também foram vedadas "condutas unilaterais ou acordos entre o responsável pela transmissão, pela comutação ou pelo roteamento e os provedores de aplicação que compro- 
metam o caráter público e irrestrito do acesso à internet" (art. 9, I). O Decreto veda acordos que "priorizem pacotes de dados em razão de arranjos comerciais" e "privilegiam aplicações ofertadas pelo próprio responsável pela transmissão, pela comutação ou pelo roteamento ou por empresas integrantes de seu grupo econômico" (art. 9, II e III).

Assim, pretendeu-se analisar com este segundo capítulo os casos concretos que envolvem as práticas anticoncorrenciais em tribunais internacionais, traçando semelhanças entre os encontrados no Brasil. Além disso, diante da inexistência de processos finalizados brasileiros, traçou-se um perfil histórico decisional do Cade, levando-se em conta a legislação constitucional, infraconstitucional e o Marco Civil da Internet. Por fim, verificou-se que importantes decisões desse tribunal - e que envolveram gigantes da economia - foram fundamentadas a partir de princípios já previamente estabelecidos, tanto os de ordem econômica quanto os relacionados ao princípio da dignidade humana. Diante desse complexo cenário, em que muitos fatores e atores podem vir a influenciar nas futuras decisões concorrenciais que envolvem os gigantes da internet, verificou-se que o Cade é capacitado para julgá-las, mas resta saber se assim o fará com coerência e fundamentação nos casos em que for demandado a solucionar.

\section{CONCLUSÕES}

A sociedade em rede, permeada pelos paradigmas tecnológico e aceleracio- nista, constitui-se como um modelo organizacional completamente diverso de qualquer outro existente até então. As mudanças no campo tecnológico acontecem muito rapidamente e impõem desafios de ordem estrutural em razão dessa velocidade. O intercâmbio entre informação e tecnologia possibilitou e foi possibilitado por esse modelo. Este não deve ser considerado, a priori, nem como bom ou mau, pois depende da utilização que se faz dessa nova composição.

Diante desse quadro, algumas empresas que operam no campo da internet se tornaram verdadeiras gigantes. Uma vez que a utilização dela é praticamente uma condição sem a qual não se é possível sociabilizar adequadamente no mundo ocidental contemporâneo, torna-se imperativo pensar na sua regulação. Ademais, sobretudo em um contexto em que diversos desafios se manifestam a uma concorrência que permita o melhor desenvolvimento de uma tecnologia tão importante na vida das pessoas e pelas quais perpassam tantos direitos.

Em um primeiro momento, visualiza-se um rearranjo e um deslocamento em relação à potencialidade do exercício de poder, fruto da sobreposição de redes globais que diluem as tradicionais fronteiras do Estado-nação. Nesse contexto, os interesses e o poder político e econômico exercido pelos gigantes da internet impõem limites a uma regulamentação democrática de demandas que se apresentam no quadro de uma sociedade em rede global. 
Assim, a partir de uma abordagem complexa, sem a pretensão de concluir definitivamente sobre a temática, foi possível verificar alguns desafios à regulação da internet no contexto brasileiro, em face do poder dos gigantes da internet. Mesmo que os ordenamentos jurídicos disponham de mecanismos de regulamentação e que as autoridades se empenhem ao máximo no cumprimento dos dispositivos legais, há muitos obstáculos decorrentes de interesses político-econômicos e de ordem tecnológica que interferem nesse contexto.

Já em segundo momento, a partir do estudo de caso no contexto internacional e, após, no Brasil, ficou evidente o esforço do Estado brasileiro em prevenir o abuso econômico por posição dominante, tanto nas relações entre empresas quanto nas relações entre empresa e consumidor. Entretanto, embora se conheça o perfil decisional do órgão antitruste brasileiro, ainda se aguarda o julgamento dos casos concretos que envolvem os gigantes da internet em solo brasileiro para uma análise mais consistente.

\section{REFERÊNCIAS}

Arendt, H. (2002). Le système totalitaire. Les origines du totalitarisme. Paris, França: Seuil.

Bauman, Z. (1999a). Globalização: as consequências humanas. Rio de Janeiro, Brasil: Zahar.

Bauman, Z. (1999b). Modernidade e Ambivalência. Rio de Janeiro, Brasil: Zahar.

Beck, U. (2013). Sociedade de Risco: rumo a uma outra modernidade. São Paulo, Brasil: 34.

Beck, U. (2002). The cosmopolitan society and its enemies. Theory, Culture \& Society,
191(2), 17-44. Recuperado de http://citeseerx.ist.psu.edu /viewdoc/download?doi= 10.1.1.312.3778Erep $=$ replEtype $=$ pdf

Bourcier, D. e De Filippi, P. (2016). Open data, big data. Nouveaux dèfis pour la vie privée. Paris, França: Maré \& Martin.

Brasil (2016). Decreto n..$^{8} .771$, de 11 de maio de 2016. Recuperado de http://www.planalto.gov.br/ ccivil_03/_Ato2015-2018/2016/Decreto/ D8771.htm

Brasil (2014). Lei n. ${ }^{\circ}$ 12.965, de 23 de abril de 2014. Estabelece princípios, garantias, direitos e deveres para o uso da Internet no Brasil. Brasília. Recuperado de http://www.planalto.gov.br/ccivil_03/_ato2011-2014/2014/ lei/l12965.htm

Brasil (2011). Lei $n .^{\circ}$ 12.529, de 30 de novembro de 2011. Estrutura o Sistema Brasileiro de Defesa da Concorrência; dispõe sobre a prevenção e repressão às infrações contra a ordem econômica. Brasília. Recuperado de http://www.planalto.gov.br/ccivil _ 03/ Ato2011-2014/2011/Lei/L12529.htm\#art127

Brasil (1988). Constituição da República Federativa do Brasil, de 1988. Brasília. Recuperado de http:// www.planalto.gov.br/ccivil_ 03/constituicao/ constituicao.htm

Cade [Conselho Administrativo de Defesa Econômical (2016). Processo Administrativo Yelp x Google, nº 08700.003211/2016-94. Recuperado de https://sei.cade.gov.br/sei/modulos/pesquisa/md _pesq _ processo _ exibir.php?0c62g277GvPsZDAxAO1tMiVcL9FcFMR5UuJ6rLqPEJuTUu08mg6wxLt0JzWxCor9mNCMYP8UAjTVP9dxRfPBcVFZUPs3cjrSbYIGEdhGWUVrgZOs-LkgCOSIJS1rExqD

Cade [Conselho Administrativo de Defesa Econômical (2013a). Processo Administrativo E-Commerce x Google, ${ }^{\circ}$ 08700.009082/2013-03. Recuperado de https://sei.cade.gov.br/sei/modulos/pesquisa/ 
md _pesq_processo _ exibir.php?2pXoYgv29q86Rn - fAe4ZUaXIR3v7 - gVxEWL1JeB-RtUgqOwvr6ZlwydloIhRNSr2Q221ByVKByYDYwsal3 _ JxuPKafcwvOhoHGvTOhF6VN9yO1O84rME0Sb3aYKzWyP2

Cade [Conselho Administrativo de Defesa Econômical (2013b). Processo Administrativo Microsoft Corporation $x$ Google, $\mathrm{n}^{\circ}$ 08700.005694/2013-19. Recuperado de https:/sei.cade.gov.br/sei/modulos/pesquisa/ md _ pesq_processo _ exibir.php?2pXoYgv29q86Rn - fAe4ZUaXIR3v7 - gVxEWL1JeB-RtUgqOwvr6ZlwydloIhRNSr2O22lByVKByYDYwsa13 _ Jxjwy0jsF2VUK9nLLMn4AapgzHPEyXU3WqUFUJvQc-tbB

Cade (Conselho Administrativo de Defesa Econômical (2011). Processo Administrativo E-Commerce x Google Shopping, $\mathrm{n}^{\circ}$ 08012.010483/2011 -94. Recuperado de https://sei.cade.gov.br/sei/modulos/pesquisa/ md _ pesq_processo _ exibir.php?2pXoYgv29q86Rn - fAe4ZUaXIR3v7 - gVxEWL1JeB-RtUgqOwvr6ZlwydloIhRNSr2O22lByVKByYDYwsal3 _ JxqldakEIsAfM40O _ nlair2nlnoNzF4h6tAzo-cc8tTVt

Cade [Conselho Administrativo de Defesa Econômical (2007). Processo Administrativo Aquisição Volkswagen, no 08012.002673/2007-51. Recuperado de https://sei.cade.gov.br/sei/ modulos/pesquisa/md _ pesq _ documento _ consulta _ externa.php?oWSl671FHvjGUnAODi8Uxt3Xc1SZ48qZCupgSiZTkaSMl3qxZ69-Uzuw3VXuXgPyS2-G9p5NbpUjhnOZVYjugx6EXUEdwmqcc6iYghhIIR0LukXp0PX56Ekl-bqYFKIW

Cade [Conselho Administrativo de Defesa Econômical (1997). Processo Administrativo Fusão AmBev, no 08000.018480/1997-28. Recuperado de https://sei.cade.gov.br/sei/modulos/pesquisa/md _ pesq_processo_exibir.php?0c62g277GvPsZDAxAO1tMiVcL9FcFMR5UuJ6rLqPEJuTUu08mg6wxLt0JzWxCor9mNcMYP8UAjTVP9dxRfPBcZlBhpWiHaAcSFcMQ4puCpyEeiAAi4 _ U2cuVuYvdWBW7
Castells, M. (2015). O poder da comunicação. São Paulo/Rio de Janeiro, Brasil: Paz e Terra.

Castells, M. (2007). A sociedade em rede: a era da informação - economia, sociedade e cultura (Majer, R. V., trad.) (10ª ed). São Paulo, Brasil: Paz e Terra,

Delmas-Marty, M. (2004). Por um Direito Comum. São Paulo, Brasil: Martins Fontes.

European Comission (2017). Anti-trust: Comissão multa a Google em 2,42 mil milhões de euros por abuso de posição dominante no mercado de motor de busca, ao dar uma vantagem ilegal ao seu próprio serviço de comparação de preços. Recuperado de http://europa.eu/rapid/press-release IP-17-1784_pt.htm

European Comission (2016). Antitrust: Commission takes further steps in investigations alleging Google's comparison shopping and advertising-related practices breach EU rules. Recuperado de http://europa.eu/rapid/press-release IP-16-2532_en.htm

European Comission (2008). Antitrust: Commission imposes $€ 899$ million penalty on Microsoft for non-compliance with March 2004. Recuperado de http://europa.eu/rapid/press-release IP-08-318_en.htm

European Comission (2007). Introductory remarks on CFI ruling on Microsoft's abuse of dominant market position. Recuperado de http://europa. eu/rapid/press-release _ SPEECH-07-539 en.htm?locale $=$ en

EUR-LEX (2008). Fixing the definitive amount of the periodic penalty payment imposed on Microsoft Corporation by Decision C (2005). Recuperado de http://eur-lex.europa.eu/legal-content/EN/ TXT/HTML/?uri=CELEX:52009XC0718(01)Efrom $=\mathrm{EN}$

FAS (2016). Appeal Court supported FAS in a dispute with "Google". Recuperado de http://en.fas.gov. ru/press-center/news/detail.html?id $=46807$ 
Fidelis, A. L. (2015). Entre o "laissez-faire" americano e o "intervencionismo" europeu: para qual direção aponta a atual investigação do Cade sobre o mecanismo de busca do Google. Revista da Defesa da Concorrência - Cade, 3(2), 65-86.

Fonseca, J. B. L. e Carmo, A. S. (2013). A Defesa da Concorrência e a Concretização dos Princípios da Ordem Econômica Constitucional. XXII Encontro Nacional do Conpedi/Unicuritiba, Direito e Economia, 40-69, Curitiba, Brasil. Recuperado de http://www.publicadireito.com. br/publicacao/unicuritiba/livro.php?gt=82

Frydman, B. (2016). O Fim do Estado de Direito: Governar por Standarts e Indicadores. Porto Alegre, Brasil: Livraria do Advogado.

FTC (2013). Statement of the Federal Trade Commission Regarding Google's Search Practices In the Matter of Google Inc. Recuperado de https://www.ftc. gov/system/files/documents/public _statements/295971/130103googlesearchstmtofcomm.pdf

Gandel, S. (2016). These Are the 10 Most Valuable Companies in the Fortune 500. Fortune. Recuperado de http://fortune. com/2016/02/04/most - valuable - companies-fortune-500-apple/

Giddens, A. (2009). A Constituição da Sociedade. São Paulo, Brasil: Martins Fontes.

Giddens, A. (1991). As Consequências da Modernidade. São Paulo, Brasil: UNESP.

Google (2014). Nossa história a fundo. Recuperado de https://www.google.com.br/about/company/history/

Migalhas (2016). TRF/4 mantém decisão do Cade que julgou anticoncorrencial cláusula de exclusividade imposta pela UNIMED de Ponta Grossa a médicos cooperados. Recuperado de http://www.migalhas.com.br/Quentes/17,MI28518,21048-TRF4+mantem+decisao+do+CADE+que+julgou+anticoncorrencial+clausula+de
Morin, E. (2003). Introdução ao pensamento complexo (4⿳亠丷厂 ed.). Lisboa, Portugal: Piaget.

Munhoz, V. (2016). Spotify: "Apple não aprovou a nova versão do app para evitar competição". Tecmundo. Recuperado de http://www. tecmundo.com.br/spotify/106758-spotify-apple-nao-aprovou-nova-versao-app-evitar-competicao.htm

Oliveira, R. T. (2007). O conceito de princípio entre a otimização e resposta correta: aproximações sobre o problema da fundamentação e da discricionariedade das decisões judiciais a partir da fenomenologia hermenêutica (dissertação de mestrado). Universidade do Vale do Rio dos Sinos, São Leopoldo, Brasil. Recuperado de http://www. repositorio.jesuita.org.br/bitstream/handle/ UNISINOS/2413/conceito\%20de\%20principio.pdf?sequence $=1$ EisAllowed $=y$

Rodotà, S. (2015). Pourquoi Internet doit devenir un "Bien Commun". Mediapart. Recuperado de https://www.mediapart.fr/journal/culture-idees/101015/pourquoi -internet-doit-devenir-un-bien-commun?onglet=full

Rodotà, S. (2008). A Vida na Sociedade da Vigilância: a privacidade hoje. Rio de Janeiro, Brasil: Renovar.

Rosa, A. (2010). L'accélération. Une critique sociale du temps. Paris, França: La Découverte.

Sadin, E. (2016). La silicolonisation du monde. L'irrésistible expansion du libéralisme numérique. Paris, França: L'Éditions l'Échappée.

Saldanha, J. M. L. (2016). A aplicação da margem nacional de apreciação pelas cortes de direitos humanos: desafios à internacionalização dos direitos humanos. Em G. Redin, J. M. L. Saldanha e M. B. O. Silva (Orgs.), Direitos Emergentes na Sociedade Global. Programa de Pós-graduação em Direito da UFSM. p. 147-171. Santa Maria, Brasil. UFSM.

Saldanha, J. M. L. (2014). Charlot, os ONNI - Objetos normativos não identificados 
— e a "arte" de decidir por standards e indicadores. Justificando. Recuperado de http://justificando.com/2014/09/02/charlot-os-onni-objetos-normativos-nao-identificados-e-arte-de-decidir-por-standards-e-indicadores/

Saldanha, J. M. L. (2013). Os desafios do "império cibernético" na era da aceleração e da informação: um "sexto continente" de liberdade perfeita ou de controle perfeito? Em J. S. Tybush, L. E. B. Araujo e R. L. Silva (Orgs.), Direitos Emergentes na Sociedade Global: Anuário do Programa de Pós-graduação em Direito da UFSM. p. 173-219. Ijuí, Brasil. Unijuí.

Santana, B. (2016). O bicho pegou: Apple responde ao Spotify, acusando o serviço de "apelar a rumores e meias-verdades". MacMagazine. Recuperado de https://macmagazine.com. br/2016/07/01/o-bicho-pegou-apple-responde-ao-spotify-acusando-o-servico-de-apelar-a-rumores-e-meias-verdades/

Santos, B. S. (2006). A gramática do tempo. Para uma nova cultura política. São Paulo, Brasil: Cortez.

Statista (2016). Google's revenue worldwide from 2002 to 2015 (in billion U.S. dollars). Recuperado de https://www.statista.com/statistics/266206/ googles-annual-global-revenue/
Supiot, A. (2014). O Espírito de Filadélfia: a Justiça Social diante do Mercado Total. Porto Alegre, Brasil: Sulina.

TI Inside (2008). UE multa Microsoft em US\$ 1,3 bi, a mais alta já aplicada a uma empresa. Recuperado de http://tiinside.com. br/tiinside/27/02/2008/ue - multa - microsoft-em-us-13-bi-a-mais-alta-ja-aplicada-a-uma-empresa/

Vieira, D. (2017). Google será processada pela Comissão Europeia por prática anticoncorrência. Tecmundo. Recuperado de https:// www.tecmundo.com.br/google/117863-google-processada-comissao-europeia-pratica-anticoncorrencia.htm

Virilio, P. (1996). A Arte do Motor. São Paulo, Brasil: Estação Liberdade.

Walker, K. (2017). The European Commission decision on online shopping: the other side of the story. Recuperado de https://www.blog.google/topics/ google-europe/european-commission-decision-shopping-google-story/ 